\title{
Influence of Ti-6Al-4V and Ti-15Zr Dental Implants on the Stress in Mandibular Bone
}

\author{
A finite element analysis study
}

\begin{abstract}
COSMIN DIMA ${ }^{1}$, DORIANA AGOP-FORNA ${ }^{2 *}$, SANZIANA BUTNARU MOLDOVEANU ${ }^{3}$, CONSUELA NORINA FORNA ${ }^{4}$
${ }^{1}$ Grigore T. Popa University of Medicine and Pharmacy lasi, Dental Medical Faculty, Department Implantology, Removable Restorations, 16 Universitatii Str., 700115, Iasi, Romania

${ }^{2}$ Grigore T. Popa University of Medicine and Pharmacy lasi, Dental Medical Faculty, Department Oral Surgery, 16 Universitatii Str., 700115, lasi, Romania

${ }^{3}$ Grigore T. Popa University of Medicine and Pharmacy lasi, Bioengineering Faculty, 16 Universitatii Str., 700115, Iasi, Romania ${ }^{4}$ Grigore T. Popa University of Medicine and Pharmacy lasi, Dental Medical Faculty, Department Implantology, Removable Restorations, 16 Universitatii Str., 700115, Iasi, Romania
\end{abstract}

\begin{abstract}
The purpose of our study was to analyze the influence of Ti-6Al-4V and Ti-15Zr dental implants, with complex implant designs, on the cortical and trabecular mandibular bone in regards to the stress value and its distribution using finite element analysis. A total of four 3D implantassemblies were modeled, each consisting of implant, abutment, abutment screw, cement layer, and ceramic crown. Implants were modeled with different macrostructure designs with focus on the main thread and microthread design as well as complex geometry details. All implants were inserted in the second molar position in the mandible bone section, consisting of two macro-structures, a $2 \mathrm{~mm}$ thick cortical bone and an internal cancellous bone. Results revealed thatsmall variations in the implant design led to a great difference in the stress values and distribution in both cortical and cancellous bone. Our results suggestno major difference between Ti-6Al-4V and Ti-15Zr in regards to the material's ability to decrease stress in the periimplant bone. However, within the same material, results revealed important differences between thread design and implant geometry concerning the stress values and stress concentration in cortical and cancellous bone in the mandibular model.
\end{abstract}

Keywords: materials, Ti-15Zr, implant design, stress, FEA

Dental implants have been widely used in oral rehabilitation of completely or partially edentulous patients. Because of the fast development of materials and technology, it has become the gold standard in restoring the function of missing teeth. How ever, implant failure still remains a prominent current issue [1]. Some of the main causes of implant failure are implant related bone resorption and inadequate osseointegration [1-3]. Both can be caused by excessive implant loading, leading to highly concentrated stress in the peri-implant bone and biocompatibility issues. These are dependent on the material and the design of de implant.

Ti-6Al-4V is one of the most frequently used Ti alloy in the manufacturing of dental implants. This material is known for its high resistance to fatigue and corrosion and low density [4]. An important factor in ensuring the biocompatibility of dental implants is the corrosion behavior of the implant material. Release in the human body of Ti$6 \mathrm{Al}-4 \mathrm{~V}$ elemental products due to corrosion has been show $n$ to lead to toxic reactions. Vanadium ions release has been associated with neurotoxicity and has been shown to lead to chromosomal damage [5-7].

In an attempt to increase biocompatibility, new materials have been proposed, such as Ti-15Zr $[4,8]$. This material offers improved mechanical properties in comparison to Ti-6Al-4V, with a tensile strength of $953 \mathrm{MPa}$, whereas that of Ti-6Al-4V is $680 \mathrm{MPa}$. Also, Ti-15Zr presents an increase in material elasticity.

The elasticity of material is believed to play an important role in reducing stress in the periimplant bone and contributing to reducing marginal bone loss which is associated to high stress concentration at crestal bone level [9]. However, in current scientific literature, it is not well documented if a relatively elastic alloy or a rigid one is more favorable in terms of reducing crestal bone stress [10-12]. And since the mechanical properties of the implant itself are in close relationship to its material and implant design it is important to analyze the two in conjunction $[13,14]$.

Implant design, with concerns over its macro design and micro design, is an important factor that influences the implant primarystability and peri-implant stress values and distribution $[15,16]$.

Current dental implant designs concern the micro design and macro design. The surface treatments influence the micro design and have a direct impact on the extent of the osseointegration. The macro design is determined by the implant geometry such as implant shape, thread shape, pitch, and helix angle which have a crucial influence for achieving optimal primary-implant stability $[13,14]$. Current studies are focusing on only certain design elements, using simple implant models and changing the geometry of one design element at a time [16-19,22].

One of the design elements of interest is the presence of microthreads in the neck of the implant that has been shown to reduce marginal bone loss around implants under long term functional loading and ensure favorable conditions for osseointegration $[14,17,18]$. However, studies are not consistent in supporting this claim. Some clinical studies have revealed no significant difference in marginal bone loss between the implant with microthreads and threaded standard implants under normal long term masticatory loads [19-21].

Another design element is the thread of the implant. According to their geometry, commercial implant threads can be divided into V-shaped, square-shaped, buttressshaped, and reverse-buttress-shaped threads [22]. It has been show $n$ that the implants with square-thread designs allow for an optimal distribution of vertical stress $[16,23]$.

* email: drdorianaforna@gmail.com; Phone: 0734117885 
However, the thread angle influences the magnitude of the resistance force when locking the implant in the bone tissues [23]. A square thread with a zero face angle was shown to increased the resistance force. In a V-shaped thread, the face angle favors the positioning of the implant, decreasing resistance forces. However, this type of thread has been shown to lead to stress concentration and bony defects [23].

With over 100 implant systems currently on the market, all with various implant shape and thread design and a scarcity of clinical studies, it remains a true challenge in selecting an implant geometry to ensure optimal long term implant stability [24-27]. In this context, it is necessary to analyze and focus on whole complex designs and materials, similar to the ones used in clinical situations in order to obtain a relevant result. In a clinical situation, one may not have the option to choose between two implants that have only one difference between them thus it is important to optimize the accuracy of simulated clinical models. Having said that, finite element analysis (FEA) is an excellent tool that is able to asses various complex implant designs with different materials and virtually simulates clinical cases before conducting clinical trials [29].

The purpose of our study was to analyze the influence of Ti-6Al-4V and Ti-Zr dental implants, with complex designs, on the cortical and trabecular mandibular bone in regards to the stress value and its distribution using finite element analysis.

\section{Experimental part}

\section{Materials and method}

A total of four 3D implant assemblies were modeled, each consisting of implant, abutment, abutment screw, cement layer, and ceramic crown. Implants were modeled with different macrostructure designs. Each presented a tapered shape but different thread geometry, V-shaped, square-shaped and plateau shape respectively. Threads were also modeled at the neck of the implant in two of the models as can be seen in figure 1 . Since the implants modeled were designed similar to ones used in clinical situations, small variations in diameter and length are present.

Assembly A consisted of a tapered implant with a Vshaped thread with a flat apex, $4.2 \mathrm{~mm}$ diameter and 11.5 $\mathrm{mm}$ length. Assembly B consisted of a tapered implant with plateau thread and dome-shaped apex, $4.5 \mathrm{~mm}$ diameter and $11.5 \mathrm{~mm}$ length. Assembly C consisted of a

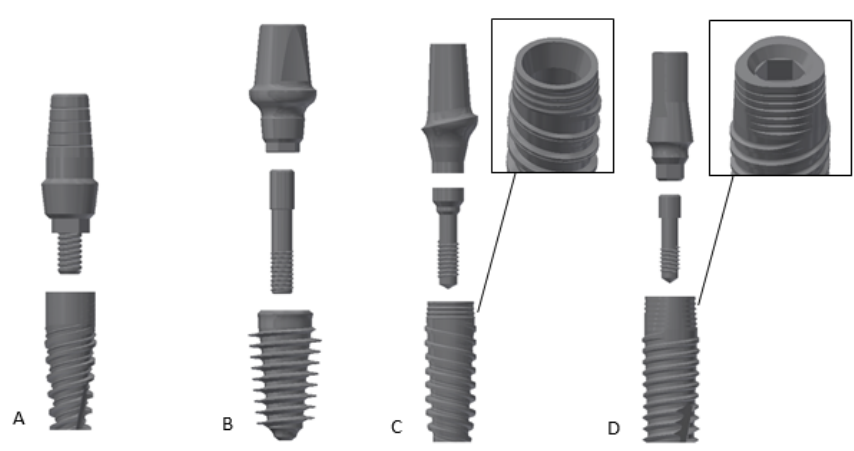

Fig. 1. Implant assemblies consisting of implant, abutment and abutment screw with various macrostructure designs. (A) Tapered implant with V-shaped thread with microthread in body and flat apex. (B) Tapered implant with plateau thread and dome-shaped apex. (C) Tapered implant with square thread, flat apex and microthreads in neck and body region with detailed view. (D) Tapered implant with microthreads in neck region, triangular shape cortical region, Vshaped thread and flat apex with detailed view tapered implant with square thread and flat apex, $4.3 \mathrm{~mm}$ diameter and $11.5 \mathrm{~mm}$ length. Assembly D consisted of a tapered implant with microthreads, triangular shape cortical region, V-shaped thread, and flat apex, $4.3 \mathrm{~mm}$ diameter and $11.5 \mathrm{~mm}$ length. A 3D mandible section consisting of two macro-structures, a $2 \mathrm{~mm}$ thick cortical bone and an internal cancellous bone was also modeled as can be seen in figure 2 .

A

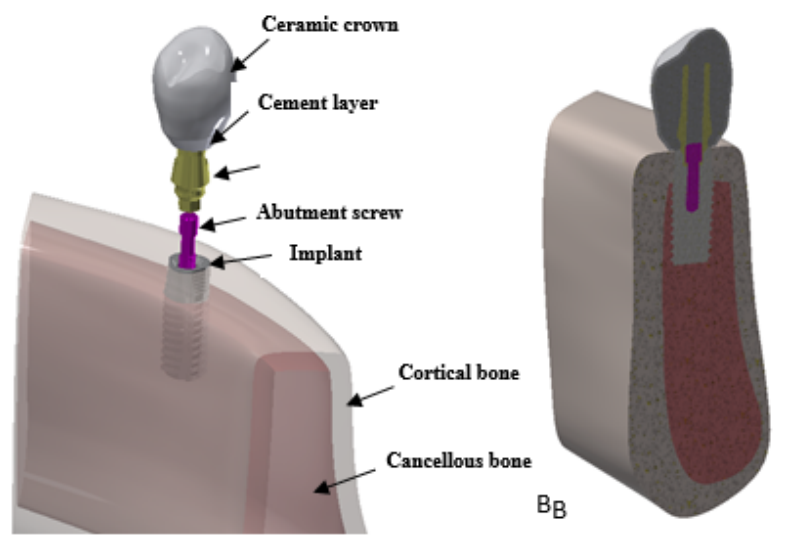

Fig. 2. (A) 3D model assembly of implant components in mandibular section. (B) Cross-sectional view of the 3D models showing internal structure

Models were constructed and processed in Autodesk Inventor Professional version 2017(Autodesk, Inc., San Rafael, CA, USA). All implants were inserted in the second molar position in the mandible bone section.

Simulations were carried out in Simulation Mechanical version 2017 (Autodesk, Inc., San Rafael, CA, USA). A static type analysis with linear, elastic and homogenous material properties was chosen for all simulation cases.

Material properties assigned for each analysis element are listed in table 1 . Boundary conditions were applied to end surfaces of the mandibular model, fixed in all directions. Contact type between bone and implantwas defined to be perfectly bonded. From a clinical perspective, perfectly bonded contact between bone and implant would translate in perfect osseointegration between the two materials.

Table 1

MATERIAL PROPERTIES OF THE 3D MODELS

\begin{tabular}{|c|c|c|}
\hline Material Component & $\begin{array}{c}\text { Elastic Modulus } \\
(\mathrm{MPa})\end{array}$ & Poisson Ratio \\
\hline Ceramic crown [30] & 140000 & 0.28 \\
\hline Ti-6Al-4V [31] & 110000 & 0.35 \\
\hline Ti-15Zr [32] & 103700 & 0.334 \\
\hline Cortical bone [33-35] & 13700 & 0.3 \\
\hline $\begin{array}{c}\text { Trabecular bone } \\
{[35,37]}\end{array}$ & 1370 & 0.3 \\
\hline Cement [38] & 10760 & 0.35 \\
\hline \multicolumn{2}{|r}{} \\
\hline
\end{tabular}

Studies have shown that introducing friction coefficient between the implant and surrounding bone as an expression of various degrees of osseointegration may artificially decrease stress in the peri-implant bone [19].

Masticatory type loads were applied on the ceramic crown based on the previous work of Himmlova et al. (2004) [29]: $114.6 \mathrm{~N}$ in the axial direction, $17.1 \mathrm{~N}$ in the lingual direction and $23.4 \mathrm{~N}$ in distomesial direction. 


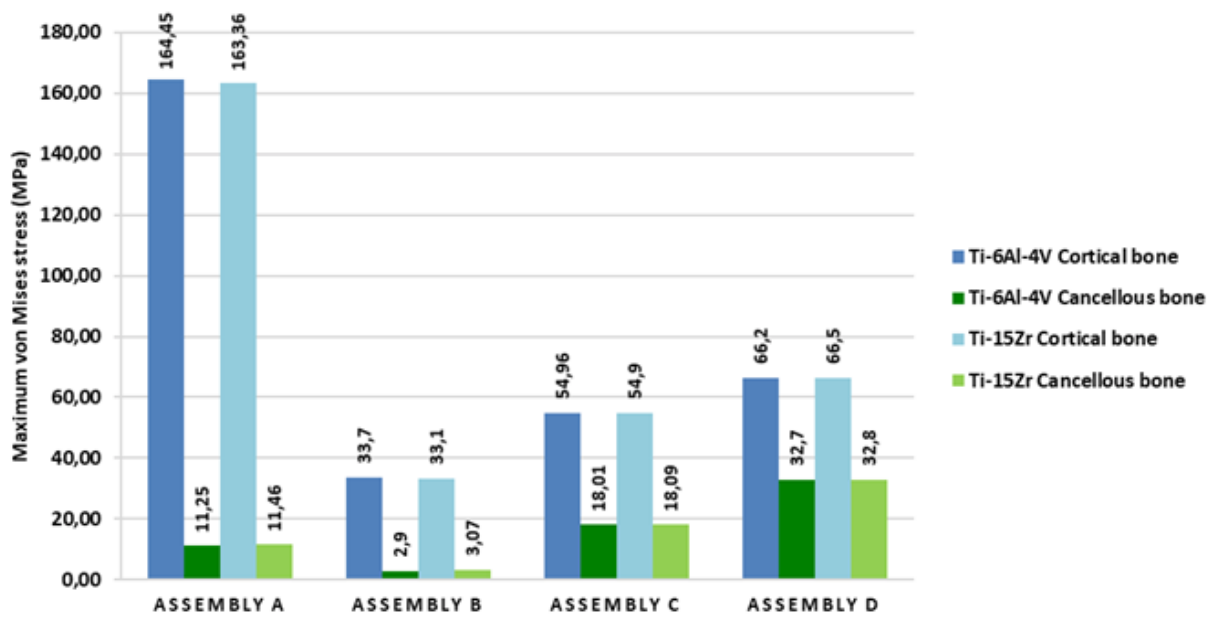

Fig. 3. Maximum von Mises stress values recorded in cortical and cancellous bone in simulated cases for Ti-6Al-4V and Ti$15 Z$ r implants.

\section{Results and discussions}

Differences in stress values both in cortical and cancellous bone were recorded in both materials, amongst all the four implant designs.

Ti-6Al-4V implants resulted in overall higher stress in the periimplant bone. Amongst the Ti-6Al-4V implants, cortical bone stress values were highest in the assembly $A$, which is the one containing the tapered implant with $V$ shaped thread with microthread and flat apex.

The values decreased when using assembly $B$, which is the one containing a tapered implant with plateau thread and dome-shaped apex.

Ti-Zr implants showed a small decrease in stress in cancellous bone in all of the simulated designs. Concerning these stress values, the highest value was recorded when using the assembly $A$ and the lowest value was recorded using assembly $B$, in which a plateau thread and domeshaped apex were present. Values of maximum von Mises stress for cortical and cancellous bone in each simulated case are presented in figure 3.

The distribution of stress in the cortical bone was similar in all simulated assemblies, showing a prevalence of the stress concentration at the crestal level. However, notable differences were found in some of the simulated cases. Assembly A led to more concentrated stress in the cortical bone as can be seen in figure 4.

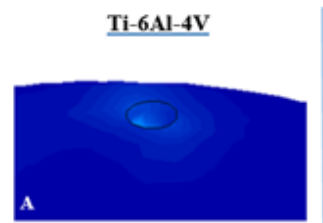

$\underline{\text { Ti-15Zr }}$
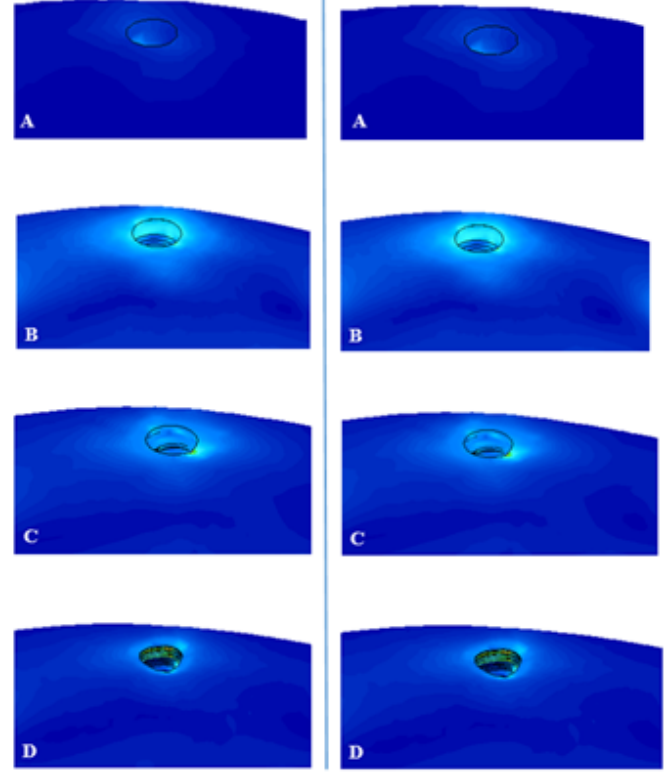

Fig. 4. Detail view of stress distribution in crestal region in simulated cases for assemblies A, B, C and D with Ti-6Al-4V and Ti-15Zr implants

When analyzing assembly $C$ we found that stress was distributed much more homogenous over a larger area at the crestal level.

The results of our study revealed differences between the Ti-6Al-4V and Ti-Zr dental implants. However, the difference in values obtained were small between the two materials in the same implant. Greater differences were found when comparing the different implants within the same material type. The results of our study revealed important differences between thread design and implant geometry concerning the stress values and stress concentration in cortical and cancellous bone in the mandibular model. Values of stress induced by masticatory forces through the implant systems can be considered difficult to asses in clinical situations. External forces applied on the bone tissue can generate bone remodeling and regeneration but if forces are excessive then they may lead to bone resorption [15, 39].

Concerning the two materials, Ti-15Zr led to a small decrease of stress in both cortical and cancellous bone amongst all implant designs. The maximum stress value in the cortical bone was found in assembly A, which contained the tapered implant with V-shaped thread with microthread in body region and flat apex, and the lowest value was found in assembly $B$ which contains the tapered implant with plateau thread and dome-shaped apex. Implants from assemblies $C$ and $D$ also led to a smaller stress value in the periimplant bone in comparison to assembly $A$. From the design point of view, this is in accordance with current studies that suggest that the presence of microthreads at implant crestal region may decrease cortical stress thus reducing bone loss and promoting osteogenesis $[40,41]$. An interesting find is that the implant used in assembly $D$, altough it contained microthreads, values of stress at cortical level were higher in comparison to assembly $C$. This difference may come from the geometry of the implant's cortical region which had a triangular shape cortical region (D) as opposed to a standard circular shape cortical region (C). This shows the importance of accuracy in geometry design analysis. Even though microthreads are more favorable in terms of reducing stress in cortical bone, the overall shape may be detrimental to the positive effect of these microthreads.

In Ti-15Zr implants, when comparing the stress values in cancellous bone, the highest value was recorded when using assembly $D$ and the lowest value was recorded using assembly B. The latter contained an implant with a plateau thread and dome-shaped apex in opposition to the implant in assembly D which presented a V-shaped thread and flat apex. A similar thread was present in the implants in assembly $A$ but here values of stress in cancellous bone were lower. The implant in the assembly $A$ also presented 
a microthread at the body of the implant alongside the main thread. This may contribute to decreasing stress in the cancellous bone as they may have a similar effect when used at crestal region. Although some studies favor the V-shaped thread because it may reduce stress in the cancellous bone as opposed to the trapezoidal shaped thread, the plateau geometry offers a larger surface of area. This translates in a larger surface area of contact between the peri-implant bone and the implant and has been to facilitate stress reduction [23, 42].

The Ti-6Al-4V implants revealed, although very small, higher stress values in both cortical and cancellous bone within the same implant design. Differences amongst the designs were consistent as the ones in the Ti-15Zr implants. These differences between the two materials rely on their mechanical properties. Ti-6Al-4V presents a greater Young's modulus thus its ability to resist deformation and increase stress transmitted in the surrounding bone as it acts as a rigid body. The difference in Ti-15Zr Young's modulus is small, $103,7 \mathrm{MPa}$ in comparison to $110 \mathrm{MPa}$ for Ti-6Al-4V. Consequently, Ti-15Zr elasticity is somewhat greater than of Ti-6Al-4V and this may translate to less stress transmitted to the periimplant bone.

Current studies also report very small differences between Ti-6Al-4V and Ti-15Zr implants in regards to the stress transmitted in periimplant bone [32,43]. In the same implant design when comparing the two materials, no differences were found in the distribution of the stress to the peri-implant bone [32].

In our study, in all simulated cases, stress was concentrated at crestal bone level. This is in agreement with several studies $[40,41]$. However, implants used in assemblies $A$ and $D$ led to a higher stress concentration at crestal level. The most favorable implant in terms of the stress distribution and value was found to be the implant used in assembly C. It showed to distribute the small stress over a larger area. This may be due to the fact that microthreads were present in both the neck and body of the implant used in combination with the square-shaped threads. This type of thread has been show $n$ to lead to an appropriate stress distribution as well as a decrease of the stress at the bone-implant interface [35].

This study has been focused on the influence of materials in complex geometry of current dental implants. Amongst the same material, differences in stress values were found when small changes in the geometry of the implant took place. They also may be influenced to some extent by the small differences in the diameter and length of the implants [43]. Our simulated implant designs do contain several intricate geometry elements, thus making the analysis more complex in determining the extent of the influence of each design element. However, these implant geometries represent clinical used implants. In a clinical situation, one may not have the option to choose between two implants that have only one difference between them thus it is important to optimize the accuracy of simulated clinical models and asses the results in the context of implant survival clinical studies [39, 43].

Our results suggest no major difference between Ti$6 \mathrm{Al}-4 \mathrm{~V}$ and Ti-15Zr in regards to the material's ability to decrease stress in the periimplant bone.

Therefore, the benefit of one material over the other should concern the biocompatibility and osseointegration. As reported in clinical studies, the Ti-15Zr does represent a more favorable option as it revealed a significantly higher bone-implant contact percentage in comparison to Ti-6Al$4 \mathrm{~V}$, after 6 weeks of osseointegration [32].
Regarding implant geometry, the issue of macro and micro design is far from being exhausted. Surface properties, small geometry variations but also intricate geometry assemblies are factors that can influence stress value and its distribution. There is a need for long term clinical studies to further investigate the in vivo outcome of such materials in the context of complex geometries, since this is just one of the many determinants in long term implant success, as are all the pro-implant and preimplant preparations [44-48]. Also, further finite element analysis studies are needed in order to investigate the complex geometry of thread designs as there are many parameters that can vary and may influence the overall result.

\section{Conclusions}

Our results suggest no major difference between Ti$6 \mathrm{Al}-4 \mathrm{~V}$ and Ti-15Zr in regards to the material's ability to decrease stress in the periimplant bone. However, within the same material, results revealed important differences between thread design and implant geometry concerning the stress values and stress concentration in cortical and cancellous bone in the mandibular model. Small variations in the implant design led to a difference in the stress values and distribution in both cortical and cancellous bone. Microthreads present in the cortical and body region of the implant proved to decrease stress in the peri-implant bone. However, the change in the geometry of the implant cortical region led to an increase in stress at the crestal level even though microthreads were used. The plateau type thread led the smallest values of stress in cancellous bone and a favorable stress distribution at crestal level. Further studies are necessary to analyze the biological tissue response to the implant material in the context of clinical type used implants that present intricate design and complex geometry.

\section{References}

1.MATHIEU V, VAYRON R, RICHARD G, LAMBERT G, et. al. Biomechanical determinants of the stability of dental implants: Influence of the bone-implant interface properties. J Biomech 2014;47:3-13.

2.BERGLUNDH T, ABRAHAMSSON I, LANG NP, LINDHE J. De novoalveolar bone formation adjacent to endosseous implants. Clin Oral Implants Res 2003;14:251-62.

3.COELHO PG, SUZUKI M, MARIN C, GRANATO R, GIL LF, TOVAR N,et al. Osseointegration of plateau root form implants: unique healing pathway leading to haversian-like long-term morphology, vol. 881; 2015.

4.OSMAN R B, SWAIN M V. A critical review of dental implant materials with an emphasis on titanium versus zirconia, Materials 2015;8(3):932958

5.SEDARAT C, HARMAND M F, NAJI A, NOWZARI H. In vitro kinetic evaluation of titanium alloy biodegradation. J Periodontal Res 200;36(5):269-74

6.RODRYGUEZ-MERCADO J J, ROLDA 'N-REYES E, ALTAMIRANOLOZANO M. Genotoxic effects of vanadium(IV) in human peripheral blood cells. Toxicol Lett 2003;144(3):359-369.

7.AFESEH NGWA H, KANTHASAMY A, ANANTHARAM V et al. Vanadium induces dopaminergic neurotoxicity via protein kinase $C$ delta dependent oxidative signaling mechanisms: relevance to etiopathogenesis of Parkinson's disease. Toxicol Appl Pharmacol 2009;240(2) :273-85.

8.HO W F, CHEN W K, WU SC et al. Structure, mechanical properties, and grindability of dental Ti-Zr alloys. J of Mat Sci: Mat in Med 2008;19(10):3179-3186. 
9.PIOTROWSKI B, BAPTISTA A A, PATOOR P ET al. Interaction of bone-dental implant with new ultra low modulus alloy using a numerical approach. Mat Sci and Eng C: Mater 2014;38(1):151-160.

10.BAL B T, ÇAGLAR A, AYDIN C et al. Finite element analysis of stress distribution with splinted and nonsplinted maxillary anterior fixed prostheses supported by zirconia or titanium implants. Int J Oral Max Impl 2013;28(1):27-38.

11.BANKOGLU GUNGOR M, YILMAZ H. Evaluation of stress distributions occurring on zirconia and titanium implant supported prostheses: a three-dimensional finite element analysis. J Prosthet Dent 2016;116(3):346-55.

12.CAGLAR A, BAL B T, KARAKOCA S et al. Three-dimensional finite element analysis of titanium and yttriumstabilized zirconium dioxide abutments and implants. Int J Oral Max Impl 2011;26(5):961-9.

13.GENG, J. P., MA, Q. S., XU, W., et al. Finite element analysis of four thread-form configurations in a stepped screw implant. J Oral Rehab 2004;31:233-239.

14.SHIN YK, HAN CH, HEO SJ , KIM S, CHUN HJ . Radiographic evaluation of marginal bone level around implants with different neck designs after 1 year. Int J Oral Maxillofac Implants 2006;21:789-94.

15.MISCH CE, BIDEZ MW, SHARAWY M. A bioengineered implantfor a predetermined bone cellular response to loading forces.A literature review and case report. J Periodontol 2001;72.

16.ABUHUSSEIN H, PAGNI G, REBAUDI A, WANG HL. The effect of thread pattern upon implant osseointegration. Clin Oral Implants Res 2010;21:129-36.

17.NIU WENZHI, WANG PENGLAI, ZHU SHAOYUE et al. Marginal bone loss around dental implants with and without microthreads in the neck: A systematic review and meta-analysis. J Prosthet Dent 2017;117:34-40.

18. LEE DW, CHOI YS, PARK KH, KIM CS, MOON IS. Effect of microthread on the maintenance of marginal bone level: a 3-year prospective study. Clin Oral Implants Res 2007;18:465-70.

19.LEE JE, HEO SJ , KOAK JY, KIM SK, HAN CH. Radiographic evaluation of marginal bone resorption around tw o types of external hex implants: preliminary study. J Korean Acad Prosthodont 2008;46:169-74.

20.RASMUSSON L, KAHNBERG KE, TAN A. Effects of implant design and surface on bone regeneration and implant stability: an experimental study in the dog mandible. Clin Implant Dent Relat Res 2001;3:2-8.

21.VAN DE VELDE T, COLLAERT B, SENNERBY L, DE BRUYN H. Effect of implant design on preservation of marginal bone in the mandible. Clin Implant Dent Relat Res 2010;12:134-41.

22.BOGGAN R S, STRONG J T, MISCH C E et al. Influence of hex geometry and prosthetic table width on static and fatigue strength of dental implants. J Prosthet Dent 1999;82:436-440.

23.CHIEN SHIH-KANG, HSUE SHUI-SANG, LIN CHIH-SHING et al. Influence of Thread Design on Dental Implant Osseointegration Assayed Using the Lan-Yu Mini-Pig Model. J Med Biol Eng 2017;37:627638.

24.BECKER W, BECKER BE, HUJ OEL $P$ et al. Prospective clinical trial evaluating a new implant system for implant survival, implant stability and radiographic bone changes. Clin Implant Dent Relat Res 2013;15:15-21.

25.ESPOSITO M, GRUSOVIN MG, COULTHARD P et al. A 5 year followup comparative analysis of the efficacy of various osseointegrated dental implant systems: a systematic review of randomized controlled clinical trials. Int J Oral Maxillofac Implants 2005;20:557-68.

26.AL-NAWAS B, KÄMMERER PW, MORBACH T, LADWEIN C et al. Tenyear retrospective follow-up study of the TiOblast dental implant. Clin Implant Dent Relat Res 2012;14:127-34.

27.HANSSON S, WERKE $M$. The implant thread as a retention element in cortical bone: The effect of thread size and thread profile: A finite element study. J Biomech 2003;36:1247-1258.

28.KORABI R, SHEMTOV-YONA K, DOROGOY A, et al. The Failure Envelope Concept Applied To The Bone-Dental Implant System. Scientific Reports. 2017;7:2051.

29.HIMMLOVA L, DOSTALOVA T, KACOVSKY A, et al. Influence of implant length and diameter on stress distribution: A finite element analysis. J Prosthet Dent. 2004;91:20-25.
30.VAILLANCOURT H, PILLIAR RM, MCCAMMOND D. Finite-element analysis of crestal bone loss around porous-coated dental implants. J Appl Biomater 1995;6: 267-82.

31.GRANDIN HM, BERNER S, DARD M. A review of titanium zirconium (TiZr) alloys for use in endosseous dental implants. Materials. 2012;5:1348-1360.

32.BRIZUELA-VELASCO A, PEREZ-PEVIDA E, JIMENEZ-GARRUDO A et al. Mechanical Characterisation and Biomechanical and Biological Behaviours of Ti-Zr Binary-Alloy Dental Implants. BioMed Research International 2017:2017,Article ID 2785863.

33.BOZKAYA D, MUFTU S, MUFTU A. Evaluation of load transfer characteristics of five different implants in compact bone at different load levels by finite elements analysis. J Prosthet Dent. 2004;92:523530.

34.VAN OOSTERWYCK H, DUYCK J, VANDER SLOTEN J, et al. The influence of bone mechanical properties and implant fixation upon bone loading around oral implants. Clin Oral Implants Res. 1998;9:407418.

35.CHUN HJ, PARK DN, HAN CH, et al. Stress distribution in maxillary bone surrounding overdenture implants with different overdenture attachments. J Oral Rehabil. 2005;32:193-205.

36.PAPAVASILIOU G, TRIPODAKIS AP, KAMPOSIORA P, et al. Finite element analysis of ceramic abutment-restoration combinations for osseointegrated implants. Int J Prosthodont. 1996;9:254-260.

37.TOLIDIS K, PAPADOGIANNIS D, PAPADOGIANNIS Y et al. Dynamic and static mechanical analysis of resin luting cements. J Mech Behav Biomed Mater 2012;6:1-8.

38.PRENDERGAST P J, HUISKESR. Microdamage and osteocyte-lacuna strain in bone: A microstructural finite element analysis. Journal of Biomechanical Engineering, 1996;118:240-246.

39.LI YINGHUI, YAMADA SHIN-ICHI, AIZAWA HITOSHI et al. Effects of a micro-thread at the implant neck on securing the quantity and quality of bone formation around implants. J Oral Maxillofac Surg Med Pathol 2019;31:13-19.

40.DE ALMEIDA EO, ROCHA EP, FREITAS AC et al. Finite element stress analysis of edentulous mandibles with different bone types supporting multiple implant superstructures. Int J Oral Maxillofac Implant 2010;25.

41.CALI M, ZANETTI E M, OLIVERI S M. Influence of thread shape and inclination on the biomechanical behaviour of plateau implant systems. Dent Mat 2018;34:460-469.

42.MEDVEDEV A E, MOLOTNIKOV A, LAPOVOK R. Microstructure and mechanical properties of Ti-15Zr alloy used as dental implant material. J Mech Behav Biomed Mater 2016;62:384-398.

43.DEMENKO V, LINETSKIY I, NESVIT K, et al. Importance of diameterto-length ratio in selecting dental implants: a methodological finite element study. Computer Methods in Biomechanics and Biomedical Engineering. 2014; 17:4,443-449.

44.SIRBU D. Standard method of implant placement. A retrospective study of the success rate of standart mid-sized implants placed in the mandible, at a period of more than 7 years post implant placement. Romanian J ournal of Oral Rehabilitation 2018;10(3):75-88.

45.GUMENIUC A. Outcome implant treatment in complete edentulism: a retrospective 5-year follow up study. Romanian Journal of Oral Rehabilitation 2013;5(1):99-103.

46.CIOLOCA HOLBAN C M, AGOP FORNA D, FORNA N C. Preparations pro-implant versus pro-prosthetic. Romanian Journal of Oral Rehabilitation 2016;8(3):72-79.

47.ANTETOMASO J, KUMAR S. Survival rate of delayed implants placed in healed extraction sockets is significantly higher than that of immediate implants placed in fresh extraction sockets. J Evid Base DentPract 2018:76-78.

48.CALIN A, AGOP FORNA D, FORNA N C. The implications of preimplantation analysis and positioning of implants in the success / failure rate of the implantation treatment. Romanian Journal of Oral Rehabilitation 2016;8(3):111-119.

$\overline{\text { Manuscript received:28.03.2019 }}$ 